\title{
Studi Ragam Motif Batik Khas di Kota Batu
}

\author{
Dena Saptarini Klimentin, Nur Endah Purwaningsih*, Idah Hadijah \\ Universitas Negeri Malang, Jl. Semarang No. 5 Malang, Jawa Timur, Indonesia \\ *Penulis korespondensi, Surel: nur.endah.ft@um.ac.id
}

Paper received: 04-03-2021; revised: 7-03-2021; accepted: 19-03-2021

\begin{abstract}
Batik is a cloth made with a special technique to produce pictorial and colored motif using basic decoration and ornaments. The motif that is made varies according to the characteristics of each city. One of them is the typical batik of Batu City where the city is known for its apples. Some of the famous batik from Batu City are Semar Batik, Nara Batikku, Batoga Batik and Shitu Batik. The aim of this study is to describe the typical batik motif of Batu City from four studios, namely Semar Batik, Nara Batikku, Batoga Batik and Batik Shitu. The data in this study were obtained from interviews, observation and document collection. The data obtained was then processed by data reduction, data presentation and decision making. The validity of the data was tested by extension of observation, increasing persistence and triangulation. The results showed that each studio has its own various typical batik motifs. Semar batik has vegetable batik, sogan apple batik and liris apple batik. The typical motif of Batik Semar is apples and vegetables. Nara Batikku has longan batik motif, red tip batik and apple cherry blossom batik. Typical motif of Nara Batikku is flowers and plants. Batoga batik has motif of toga batik, green betel leaf batik and flower batik. The typical motif of Batoga Batik is herbal plants. Shitu batik has democratic batik motif, deaf shining batik and songgokerto batik. Characteristic of shitu batik is splash batik. Of the four studios, only Batik Semar has been registered at Diskoperindag, while the other three have not. Based on the results of this study, the authors suggest that the local department can be a source of information about the new batik business. For batik entrepreneurs, this should be used as input for the emergence of new historical heritage motif. For other students, it should be used as reference material in studying the various batik motifs typical of other cities.
\end{abstract}

Keywords: batik; typical of Batu City; Batik Semar; Nara Batikku; Batik Batoga; Batik Shitu

\begin{abstract}
Abstrak
Batik merupakan sebuah kain yang dibuat dengan teknik khusus untuk menghasilkan motif bergambar dan berwarna dengan menggunakan ragam hias dan ornamen dasar. Motif yang dibuat bermacam-macam sesuai dengan ciri khas kota masing-masing. Salah satunya adalah batik khas dari Kota Batu dimana kota ini dikenal dengan buah apelnya. Beberapa batik yang terkenal dari Kota Batu adalah Batik Semar, Nara Batikku, Batik Batoga dan Batik Shitu. Tujuan dari penelitian ini adalah untuk mendeskripsikan motif batik khas Kota Batu dari empat sanggar yaitu Batik Semar, Nara Batikku, Batik Batoga dan Batik Shitu. Data dalam penelitian ini diperoleh dari hasil wawancara, observasi dan pengumpulan dokumen. Data yang diperoleh kemudian diolah dengan cara reduksi data, penyajian data dan mengambil keputusan. Keabsahan data diuji dengan perpanjangan pengamatan, peningkatan ketekunan dan triangulasi. Hasil penelitian menunjukkan bahwa setiap sanggar memiliki ragam motif batik khasnya tersendiri. Batik Semar memiliki motif batik sayuran, batik apel sogan dan batik apel liris. Motif khas dari Batik Semar adalah apel dan sayuran. Nara Batikku memiliki motif batik kelengkeng, batik pucuk merah dan batik sakura apel. Motif khas dari Nara Batikku adalah bunga dan tanaman. Batik Batoga memiliki motif batik toga, batik daun sirih hijau dan batik bunga. Motif khas dari Batik Batoga adalah Tanaman herbal. Batik Shitu memiliki motif batik demokrat, batik shining tuli dan batik songgokerto. Ciri khas dari batik shitu adalah batik ciprat. Dari keempat sanggar tersebut hanya Batik Semar yang telah terdaftar di Diskoperindag, sedangkan ketiga lainnya belum terdaftar. Berdasarkan hasil penelitian ini, penulis menyarankan bagi dinas setempat untuk dapat menjadi sumber informasi adanya usaha batik baru. Bagi pengusaha batik, agar menjadi masukan munculnya motif baru peninggalan sejarah. Bagi mahasiswa lain, agar dijadikan bahan referensi dalam meneliti ragam motif batik khas Kota lainnya.
\end{abstract}

Kata kunci: batik; khas Kota Batu; Batik Semar; Nara Batikku; Batik Batoga; Batik Shitu 


\section{Pendahuluan}

Batik adalah warisan budaya Indonesia yang mempunyai makna dalam setiap pembuatannya. Batik sendiri diresmikan oleh The United Nations Educational, Scientific and Cultural Organization (UNESCO) pada tanggal 2 oktober 2009 sebagai warisan budaya milik Indonesia. Sejak ditetapkan oleh UNESCO sebagai warisan dunia batik kian berkembang dan mendunia.

Menurut Tjahjani (2013) perkembangan batik tidak terlepas dari peran Keraton yang menggembangkannya, terutama Keraton Yogyakarta dan Surakarta. Ragam hiasnya penuh dengan filosofi dan makna seperti keberuntungan, kekayaan, kebaikan, kemakmuran, kesehatan, dan lain-lain. Namun juga perlu digaris bawahi bahwa jauh sebelum Keraton mengembangkan batik ternyata batik telah dibuat pada kerajaan Mataram.

Batik telah menjadi aset masyarakat Indonesia yang sangat berarti. Tersebar luasnya batik di seluruh Indonesia menjadikan batik lahir di setiap kota hal itu memunculkan motifmotif baru yang mengangkat kekayaan alam kota itu sendiri sehingga banyak motif yang dikreasikan dari motif dasar. Di Kota Batu batik sangat terkenal dengan motif kekayaan alamnya yaitu motif apel.

Kota Batu merupakan kota yang berada di provinsi Jawa Timur yang dahulu merupakan bagian dari Kabupaten Malang, namun pada tahun 2001 Kota Batu resmi terpisah dari Kabupaten Malang sebagai kota otonom. Kota Batu dikenal dengan keindahan alamnya yang dapat memikat kekaguman bangsa Belanda hingga Kota Batu disejajarkan dengan negara di Eropa yaitu Swiss hingga Kota Batu dijuluki De Kleine Zwitserland atau Swiss kecil di pulau Jawa

Kota Batu yang sudah menjadi Kota Wisata ini mempunyai tiga citra yaitu Pariwisata, Pendidikan, dan Pertanian. Bidang pariwisata pada Kota Batu saat ini perkembangannya sangat pesat yang dapat dilihat banyak tempat wisata yang mempunyai karakter kuat dan dapat menjadi sarana edukasi untuk anak-anak, sehingga memicu pengunjung jauh lebih banyak. Dalam bidang pertanian Kota Batu memiliki tingkat kesuburan tanah yang tinggi hingga dijuluki sebagai kota apel, karena Kota Batu merupakan penghasil apel terbesar di Indonesia dan menjadi salah satu ciri khas yang dimiliki.

Salah satu cara untuk mengenalkan citra Kota Batu agar semakin dikenal melalui Batik. Motif yang diangkat tersebut terinspirasi dari kekayaan alam, pariwisata, dan ciri khas Kota Batu lainnya, dengan terciptanya motif khas Kota Batu maka dari itu motif tersebut dipakai menjadi seragam Pegawai Negeri Sipil dan sekolah-sekolah yang khususnya berada di Kota Batu. Batik menjadi suatu yang sifatnya bertahan lama dapat digunakan untuk buah tangan oleh masyarakat luar Kota Batu, dan dapat mengangkat ikon Kota Batu pada masyarakat luar.

Batik di Kota Batu mulai dikenal pada tahun 1987 yaitu sanggar batik Raden Wijaya sebagai sanggar batik tertua yang berada di Kota Batu, kemudian pada tahun 1995 mulai dikenal sanggar batik Olive, pada tahun 1996 mulai dikenal sanggar batik Semar, seiring berkembangnya waktu batik kian menjamur dan melahirkan sanggar-sanggar batik baru di Kota Wisata Batu. Diantaranya ada empat sanggar batik yaitu Batik Semar, Nara Batikku, Batik Batoga, dan Batik Shitu. 
Tujuan dari penelitian ini adalah untuk mendeskripsikan motif batik khas di Kota Batu dari empat sanggar yaitu Batik Semar, Nara Batikku, Batik Batoga dan Batik Shitu.

\section{Metode}

Jenis penelitian ini menggunakan metode deskriptif kualitatif. Lokasi penelitian akan dilaksanakan pada empat usaha batik batik yang berada di Kota Batu yang aktif dalam memproduksi kain batik hingga saat ini dan juga usaha batik di Kota Wisata Batu. Keempat sanggar tersebut adalah Batik Semar, Nara Batikku, Batik Batoga, dan Batik Shitu.

Teknik pengumpulan data dilakukan dengan metode observasi, wawancara dan pengumpulan dokumen. Observasi dilakukan dalam penelitian ini adalah dengan cara mendatangi tempat produksi batik secara langsung kemudian melakukan pencatatan yang tersusun mulai dari pembuatan batik yang memerlukan inspirasi dalam mendesain, proses pembuatan batik dengan melakukan proses-proses yang sudah, hingga batik itu jadi. Menurut Sugiyono (2016) observasi adalah dasar semua ilmu pengetahuan. Wawancara menurut Esterberg (Sugiyono, 2016) wawancara merupakan pertemuan dua orang untuk bertukar informasi dan ide melalui Tanya jawab, sehingga dapat dikonstruksikan makna dalam suatu topik tertentu. Teknik wawancara ini dilakukan pada pemilik usaha batik dan karyawan batik memiliki beberapa kesamaan pertanyaan pada proses wawancaranya.

Bogdan \& biklen (dalam Moleong, 2014) analisis data kualitatif adalah upaya yang dilakukan untuk mengorganisasikan data, memilah-milahnya menjadi satuan, mensintesiskan, mencari menemukan apa yang penting dan dipelajari yang dapat diceritakan kepada orang lain. Analisis data dalam penelitian menggunakan reduksi data, penyajian data dan pengambilan keputusan. Keabsahan data diuji dengan perpanjangan pengamatan, peningkatan ketekunan dan triangulasi.

\section{Hasil dan Pembahasan}

\subsection{Batik Semar}

Motif yang khas dari sanggar ini adalah:

\subsubsection{Batik sayuran}

Batik bermotif sayuran ini terinspirasi dari kekayaan alam petani. Motif yang diambil adalah motif daun bayam dan tumbuhan ooi atau taemak. Ragam motif terdiri dari tiga motif yaitu Motif Utama, motif pendukung, dan isen-isen.

Motif utama yang digunakan pada batik ini adalah daun bayam yang isen-isennya adalah sawutan atau cambahan berwarna coklat pada luar daun bayam pada dalam daun menggunakan warna merah dengan isen-isen warna kuning, pada motif utama tumbuhan ooi atau taemak menggunakan titik-titik menyerong mengikuti alur tumbuhan tersebut berwarna merah dengan titik putih. Motif pendukungnya ada berbagai macam yaitu titik-titik, lemahan, bunga mawar merah, dau ooi, bunga mawar, bunga padi bunga bawang merah mekar.

\subsubsection{Batik apel sogan}

Batik yang terinspirasi dari buah khas di Kota Batu mempunyai warna coklat. Motif yang diambil adalah motif apel terdiri dari buah apel, bunga apel mekar, daun apel bunga apel 
kuncup, ranting apel pendek. Motif utama yang digunakan pada batik ini adalah apel yang isenisennya adalah titik dan garis, apel berwarna merah dan putih isen-isen warna putih, pada motif utama bunga apel menggunakan titik dan garis, bunga apel berwarna biru dan daun berwarna kuning isen-isen berwarna putih Motif pendukungnya ini garis ranting, parang, dan semen.

\subsubsection{Batik apel liris}

Batik Apel berwarna dasar merah muda dengan motif apel liris, mempunyai motif yang terdiri dari bagian apel. Inspirasi dari pembuatan batik apel karena apel merupakan buah khas yang ada di Kota Batu yang juga letak geografi sebagai penghasil apel.

Pada batik ini menggunakan motif utama apel yang warna motif tersebut adalah merah muda menggunakan isen-isen cecek tiga, titik-titik, dan bentuk, daun berwarna hijau menggunakan isen-isen garis dan titik-titik dan tangkai berwarna coklat kemudian untuk apel yang mempunyai ranting menjalar warna apel merah muda, warna daun hijau, warna bunga yang menempel pada daun adalah peach, warna bunga yang menempel pada batang menjalar adalah biru menggunakan isen-isen titik-titik. Motif pendukung digunakan dalam batik ini ada ada, kopi pecah, truntum, cecek-cecek waleran, gringsing, cecek tiga, ranting apel, lemahan tembok, sritan, blarak atau janur, bunga padi.

\subsection{Nara Batikku}

Motif yang khas dari sanggar ini adalah:

\subsubsection{Batik kelengkeng}

Batik Kelengkeng berwarna dasar coklat dengan motif bunga anggrek, mempunyai motif yang terdiri dari bagian tanaman anggrek. Inspirasi dari pembuatan batik kelengkeng karena hobi pemilik menanam bunga anggrek dan dirumah pemilik banyak bunga tersebut.

Pada batik ini menggunakan motif utama anggrek yang warna motif tersebut adalah coklat karena menggunakan pewarna alami menggunakan isen-isen titik-titik dan sawutan, calon bunga berwarna coklat menggunakan isen-isen titik-titik dan tangkai berwarna coklat menggunakan isen-isen titik-titik, daun berwarna coklat menggunakan isen-isen titik-titik, garis, dan sawutan. Motif pendukung digunakan dalam batik adalah cecek enam menggunakan motif pinggiran sawutan membentuk segitiga.

\subsubsection{Batik pucuk merah}

Jenis batik tulis berwarna dasar hijau dengan motif daun pucuk merah dan bunga anggrek, mempunyai motif yang terdiri dari bagian daun pucuk merah dan tanaman anggrek. Inspirasi dari pembuatan batik pucuk merah karena tanaman ini banyak ditanam oleh warga. Batik ini menggunakan motif utama pucuk merah dan warna motif tersebut adalah merah, ungu menggunakan isen-isen yang bermacam-macam yaitu titik-titik sawutan, kembang pari, suruhan, dan garis, bunga anggrek berwarna coklat menggunakan isen-isen titik-titik dan tangkai berwarna coklat menggunakan isen-isen titik-titik. Motif pendukung digunakan dalam batik ini adalah titik dan kedelai pada bagian pinggiran kain. 


\subsubsection{Batik sakura apel}

Sakura Apel merupakan bunga yang terdapat pada tanaman apel dilihat dari kejauhan seperti bunga sakura. Motif sakura apel merupakan gambaran dari bunga apel yang mekar seperti sakura. Jenis batik tulis berwarna dasar warna salem dengan motif apel namun yang ditonjolkan disini adalah bunganya sehingga gambar bunga lebih menonjol dari pada buahnya, mempunyai motif yang terdiri dari bagian-bagian buah apel.

Batik ini menggunakan motif utama bunga apel yang warna motif tersebut adalah merah muda menggunakan isen-isen titik-titik sawutan, dan lingkaran, buah apel berwarna merah dengan gradasi merah muda menggunakan isen-isen titik-titik dan bentuk daun berwarna hijau toska menggunakan titik-titik dan sawutan, tangkai berwarna coklat menggunakan isen-isen titik-titik. Motif pendukung digunakan dalam batik ini adalah bulatan kecil-kecil atau polkadot.

\subsection{Batik Batoga}

Motif yang khas dari sanggar ini adalah:

\subsubsection{Batik toga}

Toga merupakan tanaman obat keluarga. Motif toga merupakan gambaran dari tanaman herbal yang seperti rempah-rempah. Jenis batik tulis berwarna dasar warna-warni karena menggunakan motif sekar jagad namun yang ditonjolkan disini adalah rempah-rempahnya. Motif utama adalah tanaman herbal yang warna motif tersebut sesuai dengan warna tanaman itu sendiri kebanyakan menggunakan isen-isen garis. Motif pendukung digunakan dalam batik ini adalah garis melengkung-melengkung, bulatan, motif bunga dari bulatan, cecek lima, segitiga, bentuk seperti kembang api.

\subsubsection{Batik daun sirih hijau}

Batik bermotif daun sirih ini terinspirasi dari tanaman herbal yang kaya akan manfaat. Motif yang diambil adalah motif daun sirih dipadu dengan asam dan kunyit. Jenis batik ini adalah batik tulis. Motif utama yang digunakan pada batik ini menggunakan daun sirih yang isen-isennya adalah sawutan membentuk daun berwarna hijau dengan isen-isen warna putih, batang berwarna coklat tanpa isen-isen. Motif pendukungnya ada berbagai macam yaitu cecek tiga, bentuk bunga, rempah itu pendukung juga mbak, ada gambar daun pada bagian bawah kain.

\subsubsection{Batik bunga}

Batik bunga berwarna dasar hitam dengan motif empat macam bunga, mempunyai motif terdiri dari bunga sepatu, bunga matahari, bunga mawar, bunga pukul empat. Inspirasi dari pembuatan batik bunga karena tumbuhan herbal ini termasuk dalam kategori toga.

Pada batik ini menggunakan motif utama empat jenis bunga yakni Pada bunga sepatu berwarna merah muda menggunakan isen-isen garis membentuk bunga, daun berwarna hijau menggunakan isen-isen garis, bunga mawar berwarna dasar merah menggunakan isen-isen sawutan dan titik-titik, daun berwarna hijau menggunakan isen-isen garis dan sawutan dan tangkai berwarna hijau tanpa isen-isen. Bunga pukul empat merah muda menggunakan isenisen titik-titik. Bunga matahari berwarna kuning tanpa menggunakan isen-isen. Motif 
pendukung digunakan dalam batik ini ada pipisan jamu, motif kawung, garis penghubung motif kawung.

\subsection{Batik Shitu}

Motif yang khas dari sanggar ini adalah:

\subsubsection{Batik demokrat}

Jenis batik tulis berwarna dasar biru dan biru laut dengan motif lambang partai demokrat. Inspirasi dari pembuatan batik adalah dari warna partai demokrat dan lambang demokrat. Batik ini menggunakan motif utama lambang partai demokrat yang warna motif tersebut adalah merah dan putih tanpa menggunakan isen-isen. Motif pendukung digunakan dalam batik ini adalah bentuk pilin untuk pinggirannya, lalu ada apel dengan batik cipratnya sebagai dasar dari batik,

\subsubsection{Batik shining tuli}

Batik shining tuli adalah batik ciprat dan tulis berwarna dasar merah muda, dan hitam mempunyai inspirasi dari lambang ikatan tuli dengan nama kelompok shining tuli. Batik ini menggunakan motif utama lambang shining tuli yang warna motif tersebut adalah merah muda tanpa menggunakan isen-isen hanya menambahkan mata, alis, mulut kemudian dibawah lambang shining tuli ada bulatan kecil-kecil. Motif pendukung digunakan dalam batik ini adalah batik ciprat yang berwarna putih dengan dasar warna pink, gambar doodle dengan warna ungu, orange, dan biru dengan dasar berwarna hitam, motif apel berwarna putih dan warna pink sebagai dasar dari batik dengan isen-isen ciprat warna putih.

\subsubsection{Batik songgokerto}

Batik songgokerto berwarna dasar merah muda dan hitam dengan motif lambang dari kelurahan songgokerto. Inspirasi dari pembuatan batik songgokerto adalah dari lambang songgokerto dan kekayaan alam yang di sekitar songgokerto seperti, gunung, paralayang, tumpeng, kelinci. Pada batik ini menggunakan motif utama lambang songgokerto tanpa menggunakan isen-isen berwarna biru, merah, hijau, dan hitam. Motif pendukung digunakan ada apel yang depannya ada motif paralayang, kelinci, pegunungan, sama ada juga tumpeng.

\section{Simpulan}

\subsection{Simpulan}

Berdasarkan paparan data pada bab sebelumnya diperoleh kesimpulan bahwa inspirasi batik dapat diperoleh dari berbagai macam ide, mulai dari lingkungan sekitar, hobi, buah khas dari Kota Batu dan lain-lain. Masing-masing usaha batik memiliki ciri khasnya tersendiri seperti Batik Semar memiliki motif Batik Apel, Batik Sayuran dan Tumbuhan. Motif khasnya adalah apel dan sayuran. Nara batikku memiliki motif Batik Kelengkeng, Batik Puspa Pesona dan Batik Sakura Apel. Motif khasnya adalah bunga dan tumbuhan. Batik Batoga memiliki motif Batik Toga, Batik Daun Sirih dan Batik Bunga. Motif khasnya adalah tanaman herbal dan pipisan jamu. Batik Shitu memiliki motif Batik Demokrat, Batik Songgokerto dan Batik Shining Tuli. Motif Khasnya adalah batik ciprat. 
Pada usaha Batik Semar terdapat motif Sayuran dan Tumbuhan yang terinspirasi dari kekayaan alam petani dan tumbuhan yang ada di depan rumah, dua motif apel terinspirasi dari motif khas Kota Batu dan motif pakem yang dibuat oleh Batik Semar. Nara batikku mempunya tiga batik yang telah diteliti yaitu Batik Kelengkeng, Batik Puspa Pesona, Batik Sakura Apel. Motif khas dari Nara Batikku adalah bunga, dan dedaunan. Inspirasi terciptanya tiga batik tersebut adalah dari tumbuhan yang ada ada di sekitar.

Batik Batoga mempunyai Batik Toga, Batik Daun Sirih, Batik Bunga. Motif Khas dari Batik Batoga adalah pipisan jamu. Inspirasi dari pembuatan batik ini adalah tanaman herbal belum ada yang membuat untuk batik sekaligus untuk mengenalkan berbagai macam rempah. Tiga batik pada usaha Batik Shitu yaitu Batik Demokrat terinspirasi, Batik Songgokerto, Batik Shining Tuli. Terinspirasi dari lambang-lambang yang akan digambarkan untuk batik Motif khas yang tercipta dari Batik Shitu adalah batik cipratnya.

\subsection{Saran}

Berdasarkan kesimpulan hasil penelitian diatas, berikut adalah beberapa saran yang dikemukakan oleh peneliti. Bagi Dinas, penelitian ini diharapkan dapat menjadi sumber informasi adanya usaha batik baru, dan diharapkan Dinas terkait dapat mengetahui adanya usaha tersebut. Bagi usaha batik, peneliti belum menemukan adanya batik motif peninggalan sejarah seperti makam dinger, candi songgoriti, goa jepang, makam rondo kuning, serta penelitian ini diharapkan dapat menjadi masukan untuk munculnya motif baru, motif pendukung dan isen-isen pada setiap usaha batik. Bagi mahasiswa lain, hasil dari penelitian ini diharapkan sebagai bahan referensi untuk melaksanakan skripsi dengan tema serupa. Serta dapat menjadikan sebagai bahan evaluasi dan pertimbangan terhadap ragam motif batik.

\section{Daftar Rujukan}

Moleong, L. J. (2014). Metode Penelitian Kualitatif Edisi Revisi. Bandung: PT Remaja Rosdakarya.

Sugiyono, S. (2016). Metode Penelitian Pendidikan Pendekatan Kuantitatif, Kualitatif, dan R\&G. Bandung: Alfabeta.

Tjahjani, I. (2013). Yuk, Mbatik: Panduan Terampil Membatik untuk Siswa. Surabaya: Erlangga. 